\title{
NOVA GERAÇÃO DOS SISTEMAS DE PROPULSÃO E TRANSMISSÃO AUTOMOTIVOS
}

\author{
Carlos Mussato ${ }^{1,2}$ \\ ${ }^{1}$ MSC-Co Strategic Consulting \\ ${ }^{2}$ Membro Comissão Técnica Lubes e Fuels AEA \\ E-mail: carlos.mussato@gmail.com
}

\section{RESUMO}

O conceito da mobilidade diferencia-se hoje pelo advento da proteção ambiental, de maneira que os sistemas de propulsão atuais passam pelo critério de emissões controladas e do descarte de peças e fluidos sistematizado. Para que toda esta condição contemporânea possa ser realizada com êxito, o projeto e a fabricação dos componentes automotivos deve ser repensado no tocante à sua morfologia e sua capacidade de reciclagem. Assim não se sustentam as tecnologias que forneçam somente uma boa relação de custo/benefício em performance, pois o impacto no ciclo de vida útil dos equipamentos está acima de qualquer consideração técnica. Este trabalho visa informar ao leitor de maneira estruturada e cronológica sobre a evolução dos materiais, fluidos e projetos que se combinam e compõem os sistemas de propulsão e transmissão automotivos. Compreender esta evolução e raciocinar sobre a função de cada peça nos sistemas mecânicos e físico-químicos sob o olhar clínico da preservação ambiental, pode levar um veículo a compor o cenário do tráfego urbano pesado sem diminuição da qualidade de vida das pessoas que fazem uso deste complexo ambiente.

\section{INTRODUÇÃO}

Historicamente o combustível sempre foi um tema de simples relevância, até o início dos anos 80, quando os órgãos governamentais passaram a estipular limites de poluição para os veículos automotores a combustão interna, onde este combustível é largamente utilizado para o transporte de passageiros e de cargas. O melhor caminho para entendermos a evolução deste assunto é fazermos uma análise histórica sobre o ponto de vista das refinadoras de petróleo desde a década de 60 até os dias atuais. Assim podemos elaborar algumas questões que poderiam nos nortear nesta análise:

- O que acontece quando a combustível é queimada no motor de um veículo?

- O que é 'Octanas', e igualmente importante, pressão de vapor?

- Como a queima do combustível afeta o meio ambiente?

O propósito da injeção de combustível é levar a combustível ao exato local onde ela deve ser queimada, liberando assim sua energia química. Em um motor a combustão interna, a combustível como qualquer outro hidrocarboneto, não queima na forma líquida. Ela precisa ser vaporizada e misturada com oxigênio para entrar em ignição. O sistema de injeção faz esta mistura acontecer, bombeando-a em alta taxa de compressão e injetando-a assim na câmara de combustão, onde se localiza o cilindro do motor. Uma súbita liberação o de pressão é o suficiente para vaporizar a mistura ar+combustível, fazendo com que os cilindros recebem 
esta energia e possam finalmente realizar trabalho. A figura abaixo ilustra alguns dos ciclos de combustão interna a saber:

a)

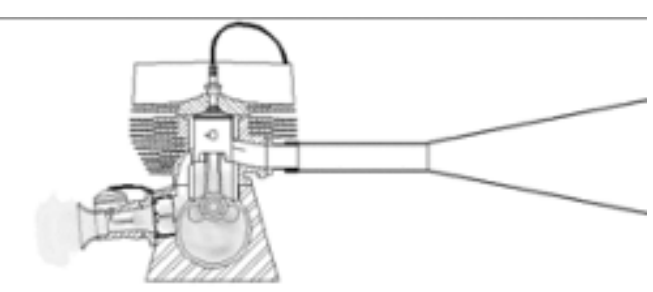

b)

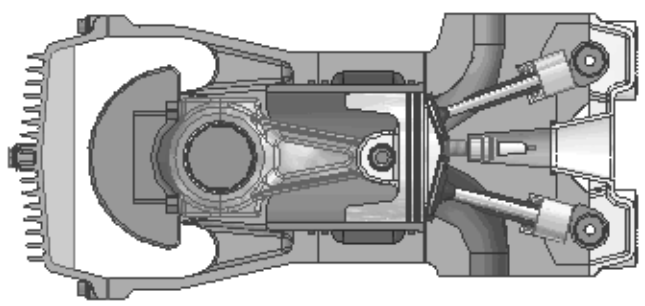

c)

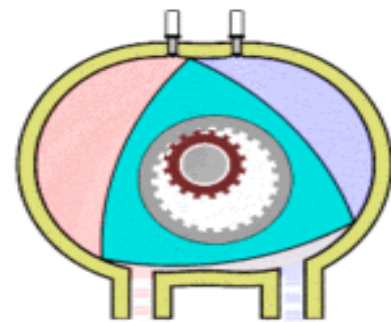

d)

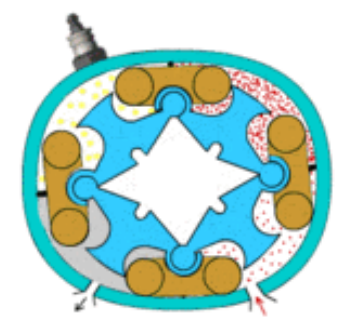

Figura 1 - Ciclos de um motor de combustão interna
a) 2 Tempos
b) 4 tempos
c) Wankel
d) Quasiturbine

O movimento de descida do cilindro até o ponto mais baixo ocorre simultaneamente com a injeção da mistura ar+combustível na câmara de combustão. Quando este ponto inferior é atingido, o sistema de injeção fecha a entrada de ar+combustível e inicia-se então a compressão dos gases injetados. Quando o cilindro então atinge sua máxima altura, ou máxima compressão dos gases injetados na fase anterior, as velas de ignição fazem o trabalho pontual de fagulha ou centelhamento para iniciar a fase seguinte, ou ignição. Neste estágio ocorre uma queima rápida do combustível em forma de vapor, como em uma explosão. Os gases então expandem-se e forçam os cilindros a se movimentarem no sentido do trabalho do motor, ou seja, produzindo força de torque com o deslocamento do cilindro do ponto mais alto para o ponto mais baixo da câmara de combustão.

Se o combustível for de boa qualidade, a queima ocorrerá de forma gradativa e suave em toda a extensão do curso do cilindro na câmara de combustão. Assim o trabalho é transmitido para o virabrequim. Na sequência os pistões fazem o trabalho de levar os cilindros do ponto mais baixo para o ponto mais alto da câmara de combustão. Antes disso, as válvulas de escape se abrem para que os gases já queimados sejam expelidos. Este ciclo se repete para cada um dos cilindros do motor a uma rotação dependente da aceleração do veículo, variando de 1000 a 6000 giros do virabrequim. Nota-se, portanto, que para ocorrer o ciclo total, quatro fases distintas devem ser atendidas a contento: admissão, compressão, expansão, escape.

Este trabalho não tem o objetivo de aprofundar os conceitos da elaboração de um combustível no tocante a questões de refinaria, mas alguns pontos devem ser observados pois afetam significativamente a emissão de gases na atmosfera. Vamos, portanto, abordar o tema 'Pressão de vaporização' [1], que por si só pode traduzir toda a problemática da combustão interna e a relevância para com o meio ambiente. 


\subsection{INFORMAÇÕES GERAIS}

\subsubsection{Considerações especiais na evolução dos motores a combustão}

A pressão de vaporização é à medida que traduz a unidade da volatilidade de um combustível, ou seja, a pressão onde na qual um combustível se mantém líquido quando oriundo da forma gasosa. Então quanto maior for a pressão de vaporização, mais volátil é um fluido. Assim, podemos raciocinar sobre o que acontece na câmara de combustão quando o tempo está frio, ou a partida é feita em baixas temperaturas, e quando o motor já atingiu a temperatura de operação, ou altas temperaturas.

Temos que entender então que quando frio, o sistema de injeção deve ter pressão de vaporização ajustada para reduzir a volatilidade do combustível, e igualmente deve ajustar a pressão para quando as temperaturas forem altas. É, portanto, diretamente proporcional e dependente da temperatura, a pressão de vaporização. Se o sistema de injeção não for capaz de equalizar as pressões de vaporização de acordo com a temperatura, pode-se ter a injeção de gotículas líquidas na câmara de combustão, o que traria problemas para a queima completa da mistura ar+combustível. Igualmente o sistema de injeção deve ajustar as pressões quando as temperaturas foram altas, pois de outra forma o combustível irá se expandir acima do permitido, impedindo que a admissão de ar seja feita a contento, e assim também traria problemas para a queima completa da mistura. Toda essa equação estequiométrica deve ser atendida para que a emissão de gases de escape seja controlada e conhecida pelo fabricante do equipamento ou veículo.

\subsubsection{Considerações especiais na evolução dos projetos e processos}

Um ponto fundamental da evolução dos sistemas de propulsão automotivos é o projeto em CAD e CAM. Desta forma as empresas passaram a otimizar os componentes para maior resistência e menor peso e tamanho. A sequência abaixo denota o modo como os programas computacionais fazer o modelamento do componente mediante uma solicitação de carga e aplicação específica:

Geometria espacial inicial -> Modelo de elementos finitos -> Topologia otimizada

Anteriormente os componentes eram fabricados mediante processos de fundição e conformação não assistidos, ou seja, os protótipos serviam também para validar a geometria e composição final do componente, incorrendo por vezes em reprovações que implicavam altos custos de fabricação. Atualmente os mesmos processos são utilizados e definidos por condições numéricas decorrentes de um projeto fiel ao modelo do componente real desejado [2]. A figura abaixo ilustra um componente de extrema importância para com a emissão de gases que é projetado e fabricado como explicado neste parágrafo: 


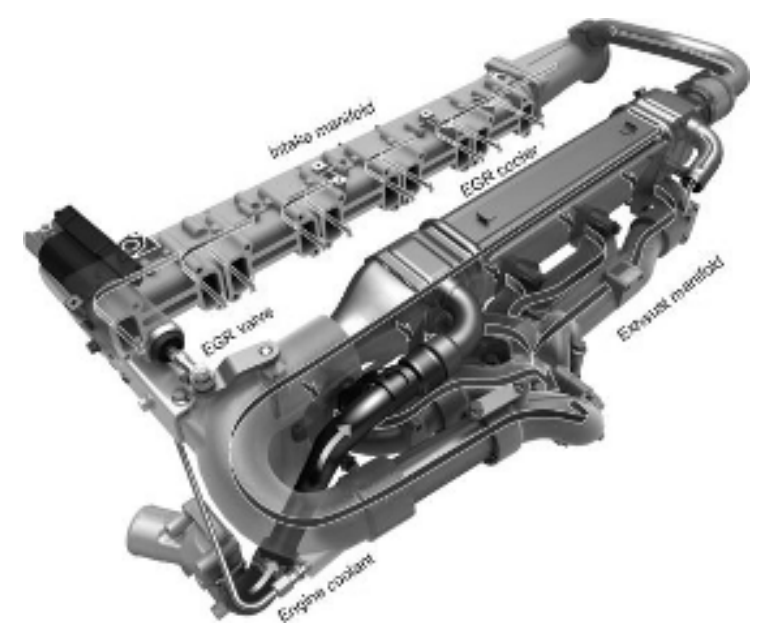

Figura 2 - Componente EGR para motores a combustão interna

Anteriormente os componentes de transmissão para elevada carga eram fabricados com dentes retos, o que eleva o nível de ruído e afeta o conforto de engate das marchas de veículos comerciais. Com o avanço das tecnologias de fabricação e projeto de conjuntos engrenados de alta complexidade como diferenciais e planetários, foi possível conceber componentes helicoidais especialmente projetados para se obter o maior grau de cobertura ou contato possível, torando o movimento mais suave e progressivo [3]. Esta característica finalmente resulta em maior rendimento do conjunto motor e transmissão, propiciando, portanto, menor consumo de energia para o deslocamento e consequente economia de combustível e emissões de gases.

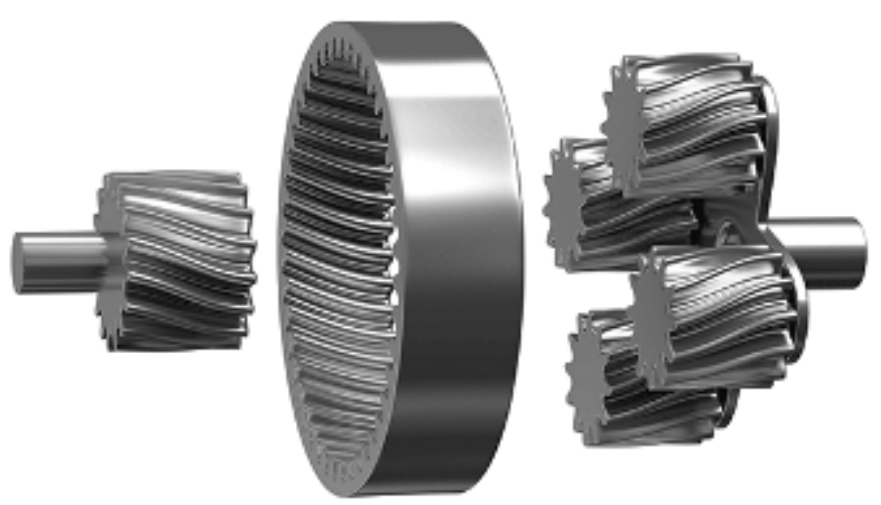

Figura 3 - Conjunto planetário helicoidal

Os componentes de alta solicitação de performance eram anteriormente projetados em uma primeira geração com modelamento sólido e matemático e em segunda geração passaram, além desta consideração de projeto, a serem revestidos metalicamente através de processos físico-químico complexos como revestimento de DLC em cilindros. Esta tecnologia já existia no mundo de ferramentas de corte para engrenagens desde a década de 90, entretanto só passou a ser usada em componentes automotivos, especialmente de motor, a partir de 2010 [4]. O motivo pelo qual esta demora ocorreu, se deve ao fato econômico e de escala de produção tecnológica, que atingiu excelência com o advento da Indústria 4.0. A figura abaixo ilustra como esta tecnologia de revestimento pode ser aplicada a um componente fundamental do motor como o cilindro (vide áreas em cinza destacadas). 


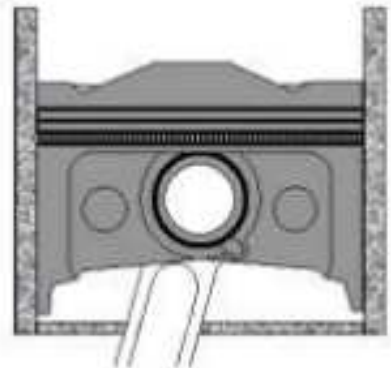

(a)

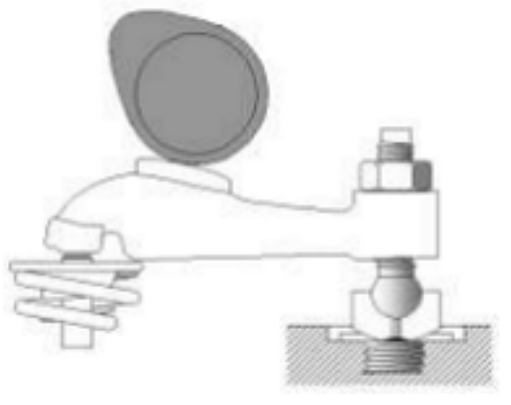

(b)

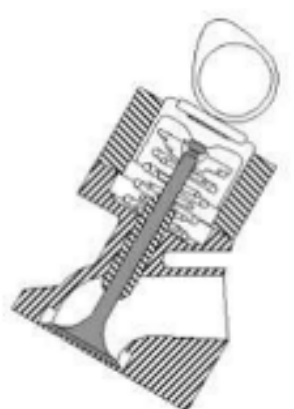

(c)

Figura 4 - Revestimento DLC aplicado a componentes automotivos

(a) Piston, (b) Camshaft, (c) Intake valve

\section{AUMENTO DA EFICIÊNCIA ENERGÉTICA}

A régua que guiou o desenvolvimento dos sistemas de propulsão e transmissão automotivos chama-se Eficiência Energética. A este termo pode-se atribuir toda responsabilidade dos sistemas mecânicos e eletrônicos atuais na obtenção do melhor desempenho de um equipamento ou veículo, sob diferentes regimes de aplicação e severidade. $\mathrm{Na}$ busca da melhor eficiência energética a inércia de movimento e frenagem é exaustivamente estudada para se minimizar as perdas energéticas e consequentemente a redução dos descartes de fluidos e sólidos em desgaste ao longo do ciclo de vida útil dos componentes.

Projetar um veículo economicamente correto denota repensar sua mobilidade ou rolamento sobre os pontos de vista de peso, tamanho e resistência mecânica. A combinação destes três fatores resulta em tecnologias modernas e tendências globais de projeto e fabricação dos componentes como redução de peso 'downsizing', aumento da resistência à fadiga, redução do atrito metálico pelo uso de revestimentos, tratamentos superficiais e uso de fluidos especiais que conferem não somente a lubrificação como a refrigeração do sistema como um todo.

\subsection{Repotenciamento de motores a combustão interna}

Os veículos automotores tiveram seus projetos elaborados de acordo com os apelos socioeconômicos de cada época, sendo inclusive a guerra um dos fatores do desenvolvimento de equipamentos de maior robustez e, portanto, menor índice de falhas. Entretanto este conceito remetia a componentes superdimensionados e de alto peso específico, já que as ferramentas para se projetar um componente mecânico também necessitaram de tempo para evoluir, e não existiam nas décadas de 30 a 70.

Como em todo segmento, existem os produtos de ataque ou prateleira, os produtos intermediários 'midstream' e os produtos 'premium' ou topo de linha. O segmento automotivo não foge deste conceito e podemos relacionar a potência dos motores à essa escala 
de conceito de produto. Assim para se atender ao deslocamento urbano necessitou-se da utilização de produtos de ataque ou veículos de baixa potência e alta economia de combustível, já que a evolução da população conta com um crescimento urbano de larga escala, onde cada veículo em circulação tem sua parcela de contribuição na emissão de gases de escape oriundos de queima de combustível [5].

Os produtos intermediários ou 'top' de linha podem ser relacionados aos motores com capacidade em cilindradas acima de 2.0. Estes veículos obviamente devem circular em menor número nos grandes centros urbanos já que demandam mais potência e consumo de combustível. O que ocorre é que na atualidade eles já coexistem aos de baixa potência e cilindradas de 1.0 a 1.6, devido ao advento da evolução tecnológica já ilustrado no capítulo anterior. A busca incessante pela melhoria da eficiência energética e redução de emissões e poluentes levou a engenharia a atingir um grau elevadíssimo de sofisticação e recursos eletromecânicos que possibilitaram um desempenho superior com um peso significativamente menor, demandando, portanto, uma menor potência ao sistema de propulsão e transmissão.

\subsubsection{Motores de 3 cilindros}

$\mathrm{Na}$ tentativa de reduzir o peso e melhorar o desempenho do veículo como um todo, o motor tem participação fundamental e exigência máxima de cuidado de projeto, porque é a parte que atua sob altas temperaturas e tem como conceito de geração de trabalho a queima de combustíveis fósseis, motivo principal da legislação atual de controle de poluição e meio ambiente.

Nesta ótica os fabricantes mundiais repensaram a propulsão reduzindo-se o número de cilíndros dos produtos de ataque ou veículos de baixa potência, migrando inteligentemente de 4 para 3 cilíndros, reduzindo-se significativamente o peso total do conjunto e possibilitando a redução de emissões como consequência final. Os grandes centros urbanos passam, portanto, a serem servidos de uma tecnologia que melhora a mobilidade sem piorar a condição ambiental, regra essa que norteia toda a evolução da indústria automobilística atual.

Para se conseguir tal façanha, os motores atuais passaram de aspirados para turbinados. A necessidade desta mudança reside no fato de se aumentar a potência via melhoramento da eficiência energética e não via superdimensionamento de componentes. Esta melhoria é conseguida através do estudo do motor como uma máquina térmica, então quanto maior for o aproveitamento do calor gerado pela combustão, maior será a eficiência energética do conjunto todo [6], já que o sistema de propulsão é responsável pela retirada do veículo do estado de repouso para a aceleração máxima. O componente fundamental desta adição tecnológica é a turbina, o sistema de admissão e escape de gases e o sistema de injeção de combustível. 


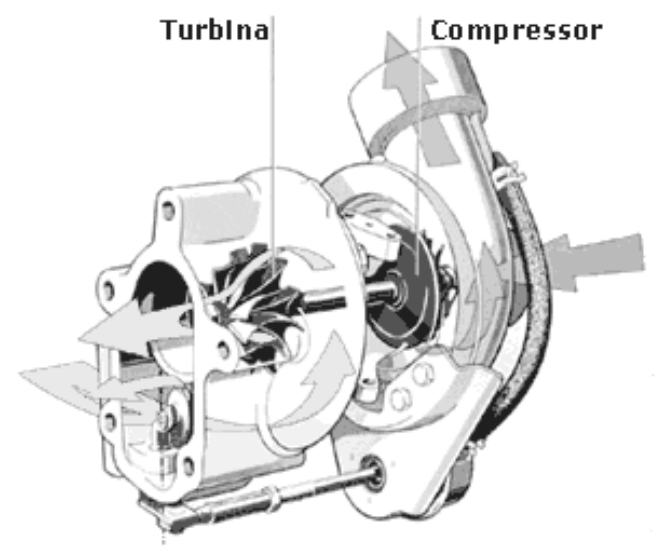

Figura 5 - Componente principal de motor turbinado

Adicionalmente à alimentação forçada da mistura ar+combustível, o sistema de injeção também foi otimizado, passando a alimentar a câmara de combustão de maneira direta. Este fator agregou benefícios à economia de combustível, entretanto obrigou os lubrificantes a reagirem contra o fenômeno da ignição à baixa rotação ou LSPI. Vale lembrar que esta condição especial só existe para a combinação de turbo-alimentação somado à injeção direta de combustível. Para solucionar este problema a indústria de lubrificantes desenvolveu a categoria ILSAC GF-6, que evita danos ao motor turbinado e com injeção direta de combustível TGDI.

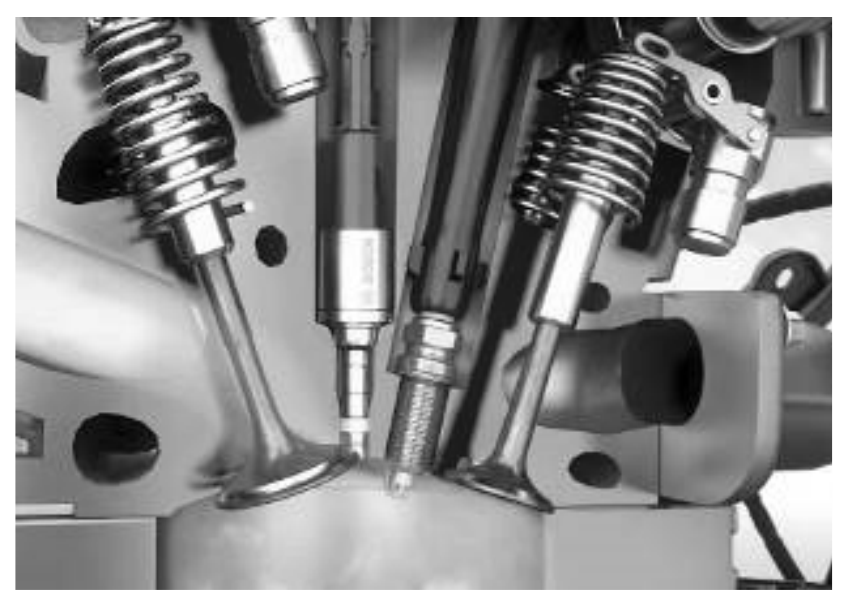

Figura 6 - Injeção direta de combustível GDI

Em ambos os modos de mistura ar+combustível, estratificado e homogêneo, há geração de óxido de nitrogênio NOx. A geração de composto é inerente ao uso do combustível independente da tecnologia de injeção direta ou convencional. Os catalisadores são componentes redutores dos teores de NOx, entretanto é impossível zerar este residual com um catalisador normal de 3 vias. Somente com o surgimento dos catalisadores de armazenagem de NOx foi possível atender às normas de emissões de poluentes EURO 4. Então vemos que para cada benefício atingido corresponde um desafio tecnológico a ser superado. 
A principal característica de projeto que salienta a inovação dos motores de 3 cilíndros é sua construção modular, ou seja, o motor é composto de um conjunto de 9 componentes cada qual com uma otimização de funcionamento que garante alto desempenho e ótima eficiência energética. São eles: (1) catalisador com turbo-compressor, (2) sistema de controle do comando de válvulas por correia dentada e correias poli-V, (3) cárter, (4) bloco e (5) cabeçote com ligas de alumínio de alta resistência mecânica e ótima dispersão térmica, (6) virabrequim e conjunto pistão-manivela com otimização de geometria, (7) coletor de admissão com intercooler, (8) carcaça de válvula termostática com a bomba do líquido de arrefecimento acoplada e (9) alojamento dos comandos de válvula.

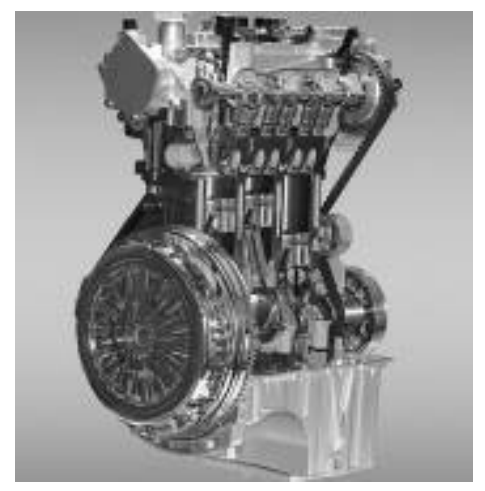

Figura 7 - Exemplo de um motor de 3 cilíndros

\subsubsection{Aspectos de acabamento superficial}

O bloco do motor é feito de Alumínio fundido, bem como a camisa dos cilíndros, ancorada por uma cobertura fundida que garante assim uma alta rigidez ao bloco. As camisas dos cilíndros tiveram o acabamento superficial brunido afim de reduzir a distorção. Isso também permite que a tensão dos anéis seja reduzida e consequentemente o atrito metálico do par cilindro-camisa. O consumo de óleo é por demais afetado por condições de assentamento dos componentes metálicos e consequente aumento de folgas. Neste projeto otimizado com as baixas distorções conseguidas por uma rugosidade superficial extremamente baixa do conjunto cilindro-camisa, diminui-se também o consumo de lubrificante e, portanto, contribui para uma condição ecológica mais favorável.

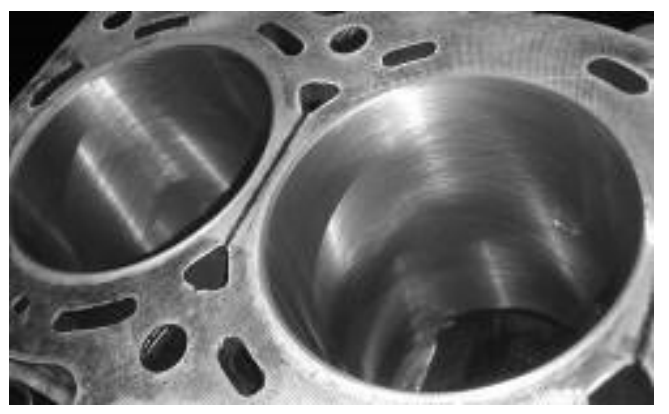

Figura 8 - Acabamento superficial proveniente de processo de brunimento 


\subsubsection{Aspectos de projeto e materiais}

O sistema de alta pressão de combustível é utilizado pela primeira vez com pressões de até 250 bar. O projeto otimizado da geometria do sistema de injeção de combustível, resulta em uma ótima formação da mistura ar+combustível em todas as faixas de operação do motor. Materiais nobres como aço inoxidável foram utilizados na composição do tudo distribuidor do sistema de injeção de combustível, conferindo alto ciclo de vida do componente e, portanto, baixo descarte de peças, que reduz também a contaminação do meio ambiente e reciclagem de componentes metálicos.

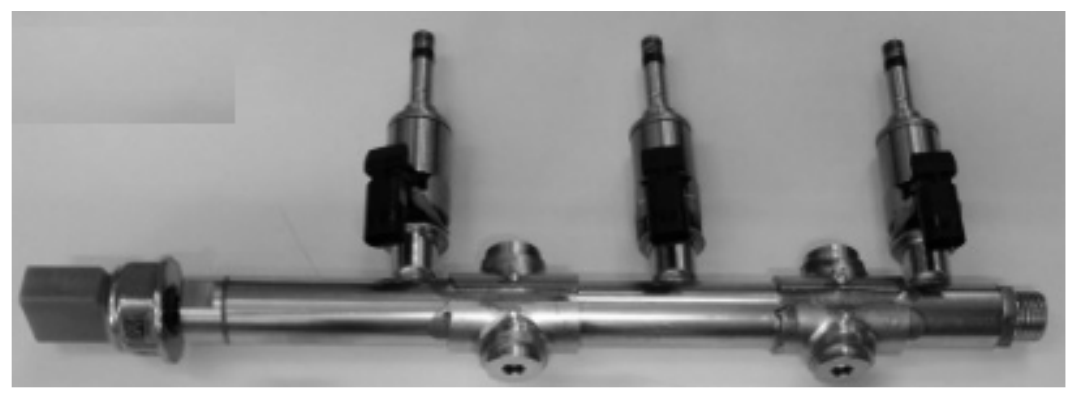

Figura 9 - Sistema de injeção para motor 3 cilindros modelo TSI

\subsubsection{Aspectos de tecnologia embarcada dos motores}

Chama-se tecnologia embarcada ao conjunto de sofisticação mecânico-eletrônica de um equipamento ou conjunto. Neste caso dos motores de 3 cilíndros, houve a adição de duas sondas lâmbida para garantir a estequiometria da mistura ar+combustível. A primeira sonda é instalada antes do catalisador e regula justamente a mistura, já a segunda sonda é posterior ao catalisador e lê os dados de emissões gerados pelo controle da primeira sonda, de maneira que faz o ajuste inteligente de sinal para correção de qualquer irregularidade na composição da mistura ar+combustível, garantindo assim uma queima perfeita e uma alta eficiência energética, já que a queima do combustível ocorre de forma completa dentro dos 4 ciclos do motor.

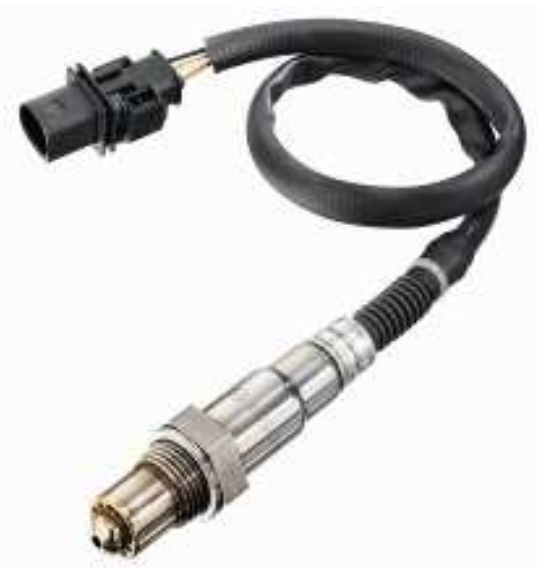

Figura 10 - Sonda lâmbida para motor 3 cilindros modelo TSI 
O sinal captado pela sonda lambida é medido continuamente, devido a regulador lambda contínuo. Isso significa que este componente analisa todas as nuances de composição entre mistura pobre e mistura rica, sendo, portanto, muito mais precisa a correção estequiométrica.

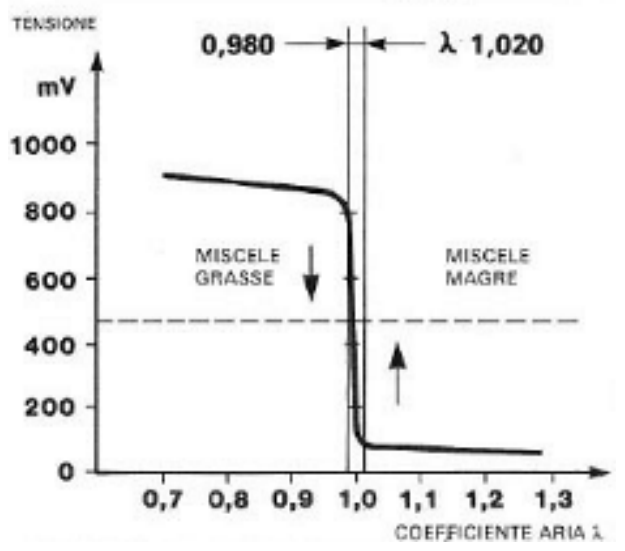

Figura 11 - Gráfico tipo de uma sonda lambda

\subsection{Revisão de projeto de motores a combustão interna}

Esta revisão se refere aos motores de maior potência e cilindrada 2.0. Estes motores contam com superalimentação e injeção direta de combustível. Como premissa para o desenvolvimento dos motores, os seguintes objetivos foram estipulados e garantidos:

- Redução do preço final ao consumidor em função de uma fabricação em larga escala dos componentes e barateamento da fabricação dos mesmos

- Adequação de montagem do motor de forma transversal e longitudinal, válida para os distintos modelos de veículos do fabricante

- Cumprir com a legislação vigente do controle de emissões de gases poluentes e do controle de ruído do conjunto

- Prover equilíbrio entre o rendimento mecânico e o termodinâmico, através de uma estrutura compacta

- Facilitar a manutenção e reparação de peças especialmente solicitadas no pós-venda

Os motores revisados de cilindrada alta 2.0 proporcionam alta potência a qualquer regime de rotações, atingindo assim uma potência máxima de $200 \mathrm{CV}$ a partir de 5000 RPM. Igualmente mantém o torque elevado e constante durante largo range de rotações do motor, graças a um sistema de distribuição variável de admissão e consequente ótimo preenchimento dos cilíndros. A questão de consumo de combustível foi atendida mantendo-se uma boa resposta e retomada do motor, além do conforto de condução causado por esta relação balanceada entre torque e potência. 


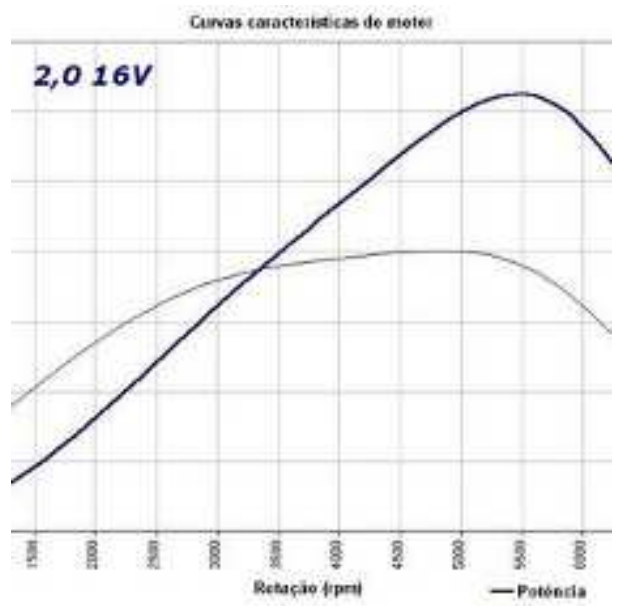

Figura 12 - Curva característica de um motor 2.0 TGDI

Os motores são máquinas térmicas e produzem trabalho em função da relação de pressão e volume de deslocamento do cilindro proveniente de um processo de queima por incitação da massa ar+combustível. Todo o desenvolvimento da engenharia automobilística é, portanto para se otimizar esta condição de aproveitamento de calor e rendimento de trabalho mecânico. A seguir identifica-se cada uma das partes constituintes do desenvolvimento dos motores a combustão, com ênfase na importância e grau de evolução de cada uma. Assim pode-se ter uma visão sistemática de como os veículos atuais tornaram-se mais eficientes e menos poluentes.

\subsubsection{Ciclo motor de 4 tempos}

Este ciclo predomina em motores de pequena a alta potência, consumindo combustíveis líquidos e/ou gasosos de alta octanagem. O ciclo tem larga aplicação principalmente para os veículos de passeio e de transporte rodoviário de cargas leve e pesado. As vantagens comuns são que geram menos poluentes, menos ruído e consumo, e menor frequência de manutenção que os equivalentes rotativos e wankel. As desvantagens estão no preço inicial maior do veículo e manutenção mais complexa que seus equivalentes. Abaixo identifica-se os principais pontos de desenvolvimento em um motor 4 tempos, seja Otto ou Diesel:

- Sistema de admissão

○ Ignição da mistura ar+combustível

- Sistema de escape

- Tratamento dos resíduos

- Combustão

- Retardamento químico

- Propagação da frente de chama

- Combustão esparsa

- Controle do ciclo de combustão

- Detonação

- Injeção 
A velocidade de combustão é ajustada para diversos combustíveis. As maiores velocidades de queima ocorrem entre o regime estequiométrico e o regime ligeiramente rico. Assim o aumento do volume de combustão não queimado implica em redução da temperatura da câmara de combustão, por isso reduz a velocidade de chama e gera maior consumo. $\mathrm{O}$ termo 'mistura rica' se refere a uma maior porção de combustível em solução com o ar atmosférico. Inversamente pode-se deduzir sobre a mistura pobre.

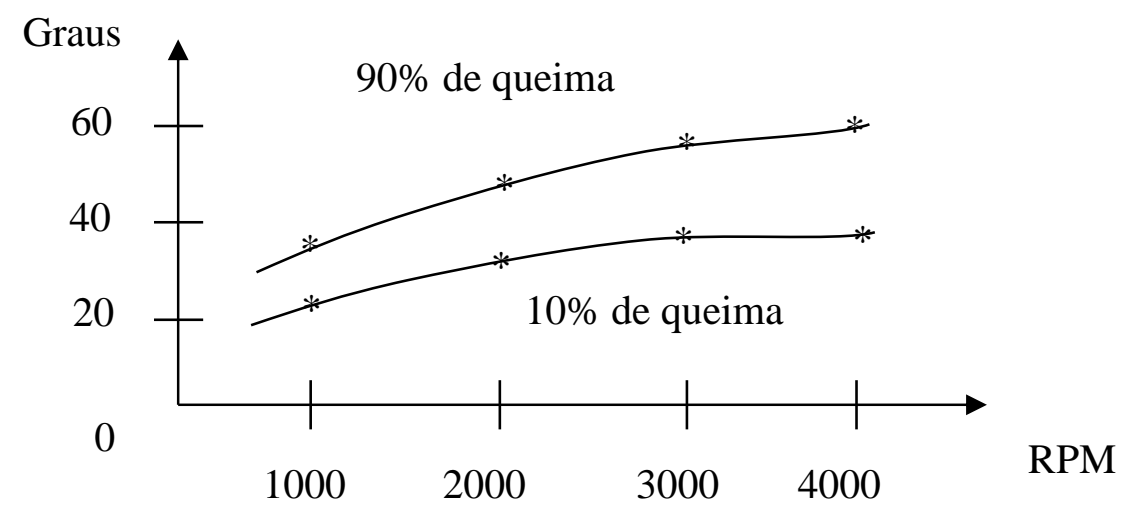

Figura 13 - Curva de duração de combustão

Observa-se pelo gráfico que a duração de combustão não aumenta significativamente com o aumento do RPM, então a combustão depende também de outro fator importante: a turbulência. Para estimular este fenômeno a geometria da câmara de combustão foi criticamente estudada, de modo a aumentar a turbulência na medida em que a compressão ocorre, propiciando assim uma combustão ideal, sem residual líquido após um ciclo.

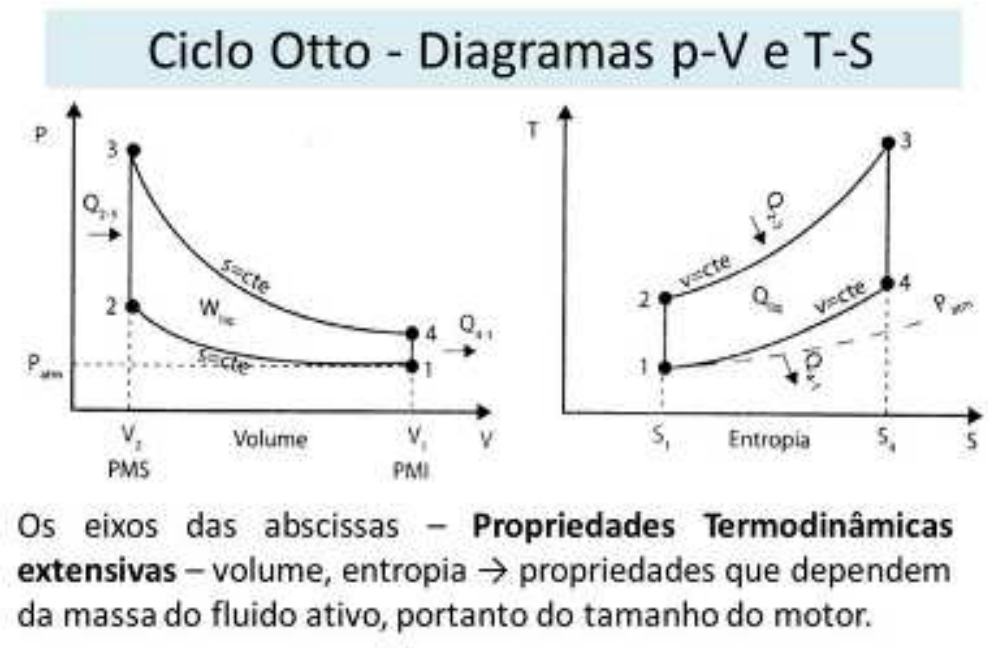

Figura 14 - Ciclo Otto ideal

\subsection{Evolução dos sistemas de transmissão e seus materiais}

Os polímeros encontraram aplicação ideal também nos sistemas de transmissão automotivos, oferecendo maior resistência mecânica sem comprometimento da afinidade físico-química. O plástico de engenharia [7] tem a vantagem adicional de ser facilmente processado de maneira econômica. Após alguns anos de estudo e desenvolvimento em transmissões CVT, os pesquisadores de materiais conseguiram construir um segmento de 
engrenagem de eixo de transmissão usando uma poliariletercetona moldada em torno de aço que era robusto o suficiente para substituir o latão revestido.

Apesar da exposição a forças centrífugas e lineares em altas temperaturas, o termoplástico oferece uma solução muito mais durável e mais leve. Embora em constante contato com o acionamento por correia, trabalha fornecendo características estáveis de aceleração e torque, com excepcional resistência ao atrito e ao calor. Isso se deve à durabilidade, impacto e resistência à tração do polímero e baixo coeficiente de atrito. As transmissões CVT não possuem alívio quanto ao atrito no flanco de retração, como ocorre com a transmissão por engrenagens [8]. Daí a importância fundamental do desenvolvimento de novos materiais para o sucesso desta aplicação.

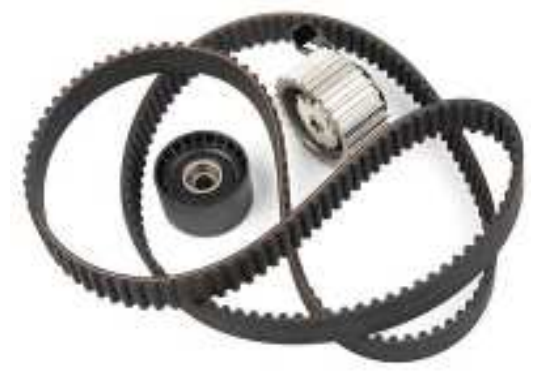

Figura 15 - Correia sincronizada da transmissão principal com material polimérico

O avanço tecnológico dos veículos comerciais, utilizando projetos de motores eletrônicos, com a possibilidade de torques diferenciados para as marchas, aliado à uma maior potência para atender à uma condição de carga e terreno, tipicamente severos como o Brasileiro, implicou em uma evolução providencial das transmissões, de forma a atender à cada um dos requisitos de exigência mecânica e de dirigibilidade. Também as exigências ambientais dirigidas pelos programas de redução de emissões, influenciaram sobremaneira as transmissões no tocante à torque e temperatura de operação.

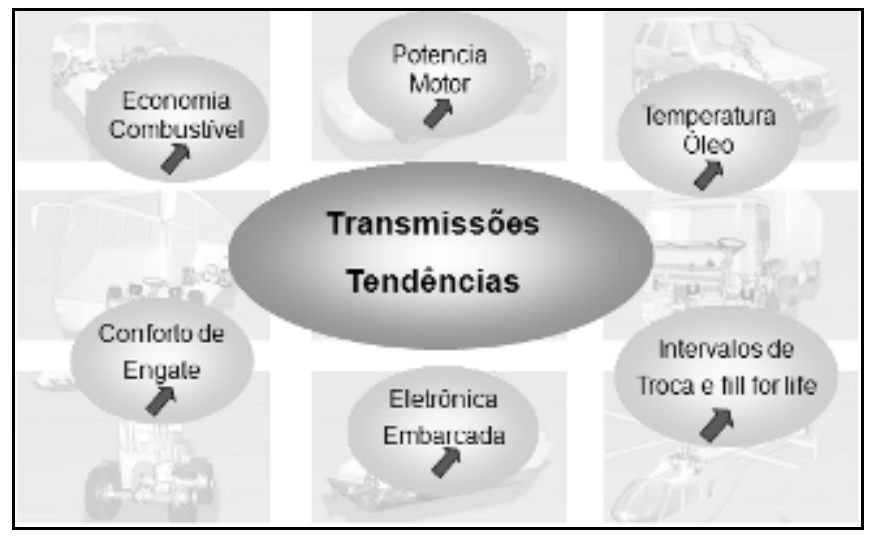

Figura 16 - Fatores de desenvolvimento das transmissões automotivas

A topografia do terreno é um fator implicante nos modos de falha dos componentes do veículo como um todo. Variações de piso quanto à aderência, aclives e declives acentuados, altitude e temperatura ambiente, são fatores extremamente importante de projeto das transmissões e devem ser mapeados para um dimensionamento correto. O compromisso de uma frota é transportar com eficiência, segurança e conforto. Estes requisitos são pensados no projeto da transmissão, de forma a oferecer ao motorista, opções de escalonamento de 
marchas que atenda às nuances de terreno encontradas, mantendo a capacidade de tração do veículo. Para que isso seja possível, as transmissões de última geração para veículos comerciais passaram de um patamar de 20 programações para 100, o que implica que a eletrônica lê e informa percursos à cada 50 metros, permitindo ajuste de escalonamento de marchas mais adequado para a economia de combustível.

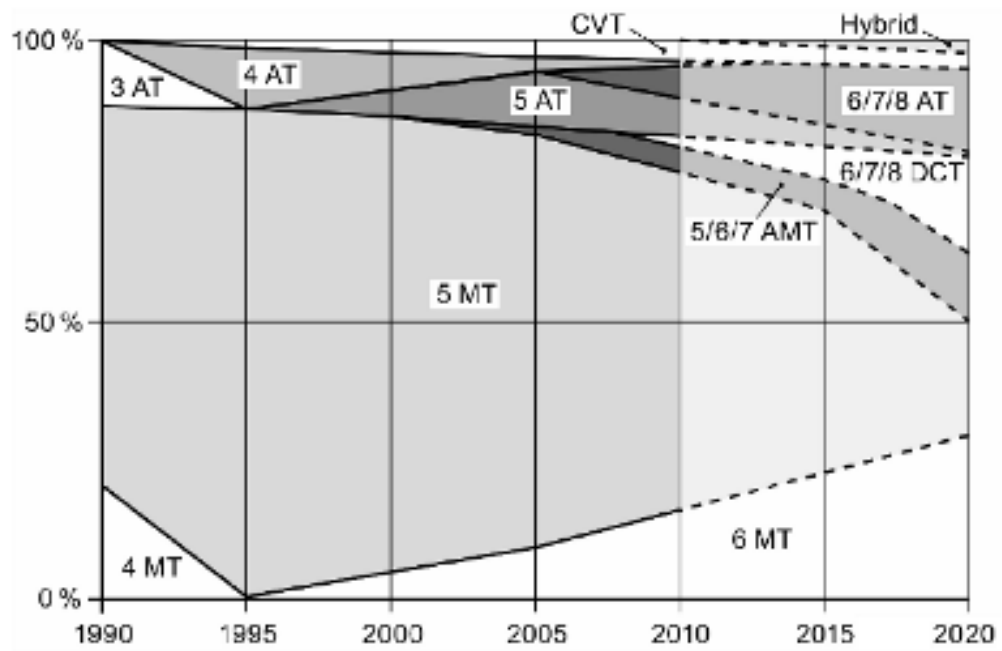

Figura 17 - Evolução do escalonamento de marchas das transmissões automotivas

\subsubsection{Evolução da tecnologia de fabricação das engrenagens}

Entre os flancos dos dentes dos pares engrenados, há uma folga de projeto, que diminui com a ação do torque do motor. Este movimento gera calor e elevação do atrito entre os flancos dos dentes. Para garantir que as partes metálicas não se fundam e que a temperatura de operação seja atenuada, os lubrificantes assumem papel fundamental neste requisito oferecendo proteção metálica por resistência de filme. O projeto do set de engrenagens deve obedecer, como em todo projeto mecânico, à uma otimização do custo de fabricação. Para isso, explora-se a condição de micro geometria do dentado, em substituição à dimensionamentos de largura e material das engrenagens.

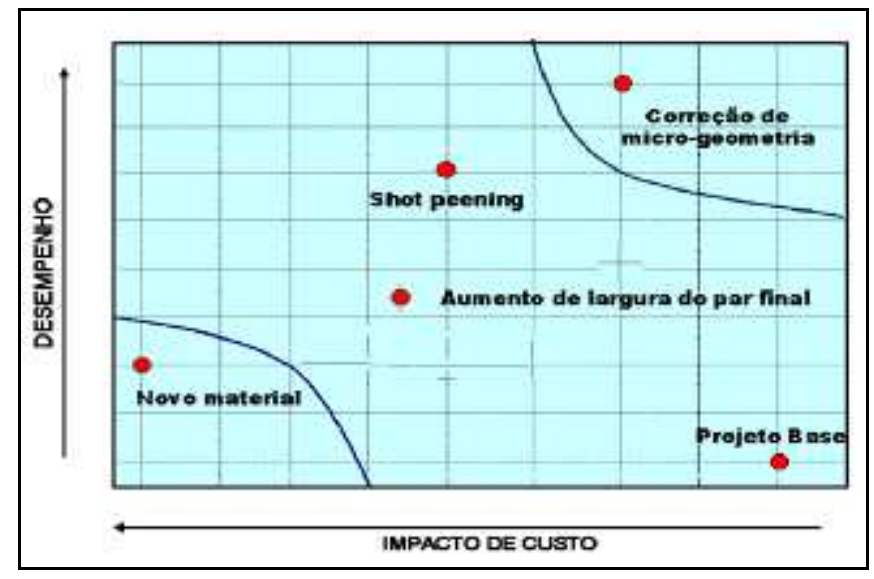

Figura 18 - Mapeamento de escolhas de processo e material para transmissões

O critério de projeto desenhado na figura acima demanda grande tecnologia de fabricação das engrenagens, com desvios geométricos projetados da ordem de $0,005 \mu \mathrm{m}$ em 
toda a extensão do dentado. Estes valores obedecem à critérios de redução de ruídos e aumento de vida útil do componente, devido ao estudo do contato entre os flancos. $\mathrm{O}$ desprendimento metálico é, portanto, diminuído através deste recurso de projeto, propiciando uma ação dispersante do lubrificante mais eficaz.

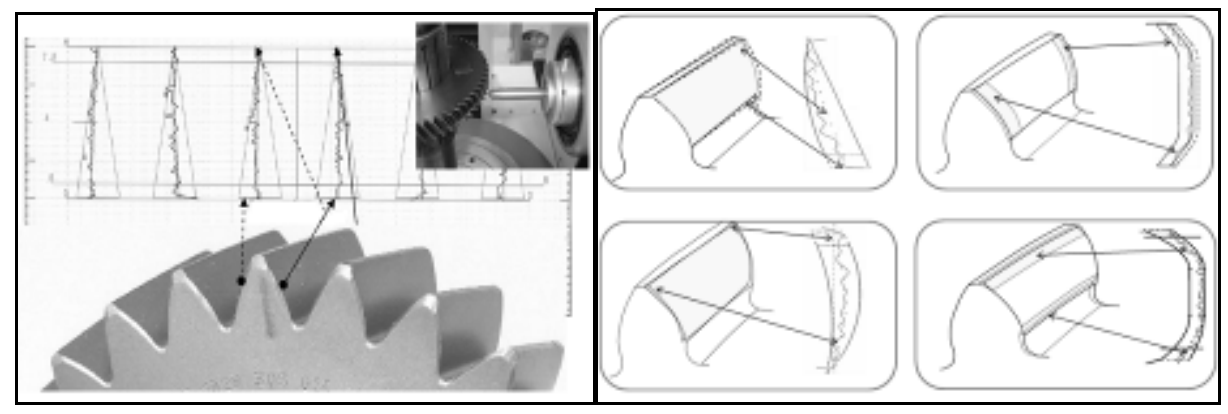

Figura 19 - Retificação de dentes com micro geometria

As tecnologias de retificação dos dentes de engrenagens utilizam rebolos cerâmicos e galvânicos. Estes últimos dispensam o uso de processo Shot Peening ainda que em baixas velocidades de corte $(<30 \mathrm{~m} / \mathrm{min})$. Os grãos de nitreto cúbico de boro conferem usinagem por abrasão e deformação simultaneamente, conferindo grande resistência à fadiga e baixíssimo desprendimento metálico no período inicial de uso da transmissão, colaborando, portanto, com a eficiência do lubrificante utilizado e aumentando o período de troca do mesmo, já que o desprendimento metálico é a principal causa de deterioração do conjunto mecânico. A figura abaixo ilustra o acabamento superficial dos flancos dos dentes de uma engrenagem retificada com processos de última geração e rebolos de nitreto cúbico de boro CBN.

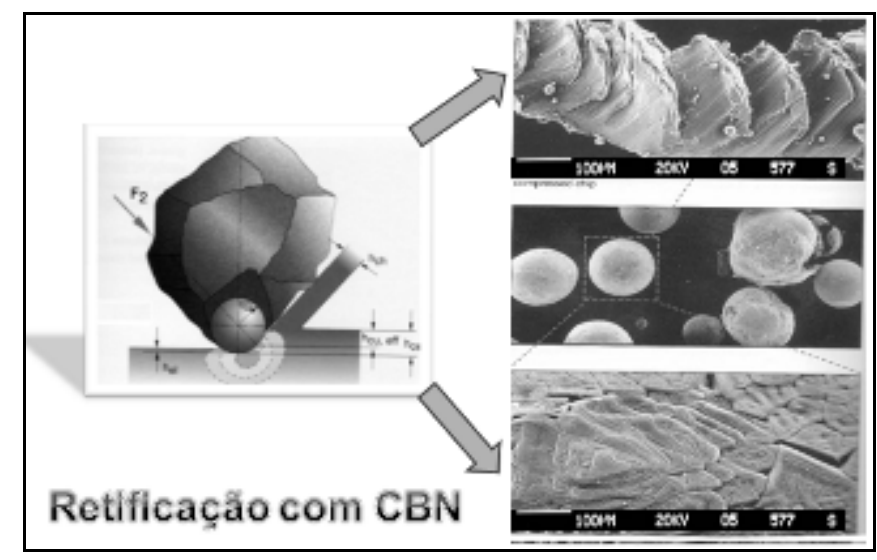

Figura 20 - Micrografia da superfície retificada com CBN

\subsection{Evolução dos fluidos utilizados nos projetos veiculares}

O projeto dos lubrificantes prevê limites de variação da viscosidade em função das condições de uso, predominantemente temperatura, tempo de operação, contaminação e regime de carga do veículo. Todos estes fatores combinados ao extremo, implicam em grande responsabilidade do lubrificante para a durabilidade do motor e transmissão. Uma das formas eficientes de se proteger o equipamento é monitorando-se o lubrificante. Conhecendo-se a 
viscosidade de cisalhamento do mesmo, pode-se acompanhar a vida útil do equipamento, evitando modos de falha como Pitting nos dentes das engrenagens.

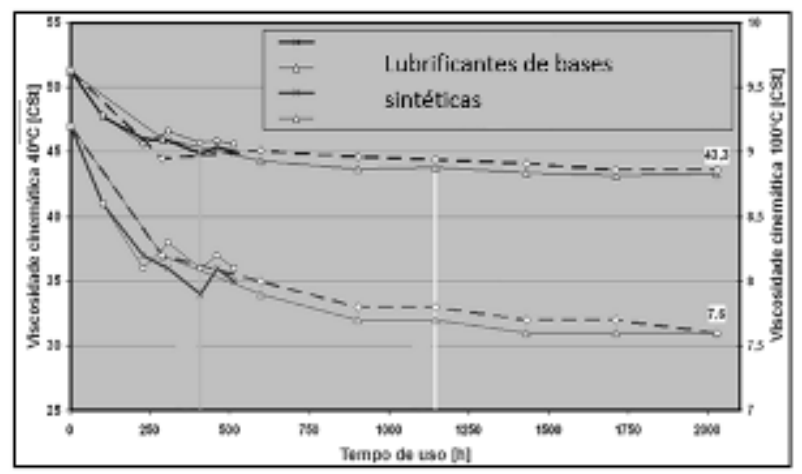

Figura 21 - Ensaio de cisalhamento de película KRL

Finalmente as condições de contorno da homologação dos lubrificantes são conhecidas e a ponderação de cada item de desempenho é comparada, para destinar o lubrificante corretamente à aplicação. Uma vez escolhido a lubrificação ideal para o equipamento, pode-se registrar a qualidade do lubrificante de primeiro enchimento através de uma checagem via Infravermelho da condição sem uso ou $0 \mathrm{Km}$. Desta forma evitam-se problemas de desgaste prematuro do equipamento em decorrência do uso de lubrificantes não homologados pelo fabricante. É importante que a escolha do lubrificante automotivo atenda a uma diversidade de fatores técnicos e econômicos para o sucesso da operação em pós-venda. Um mapeamento do desempenho de 3 lubrificantes distintos pode elucidar ao fabricante em qual nicho de aplicação este pode ser aplicado sem comprometimento da vida útil do equipamento. A figura abaixo ilustra um caso de análise entre 3 fluidos distintos em desempenho e custo, aplicados para transmissões de veículos comerciais de aplicação severa.

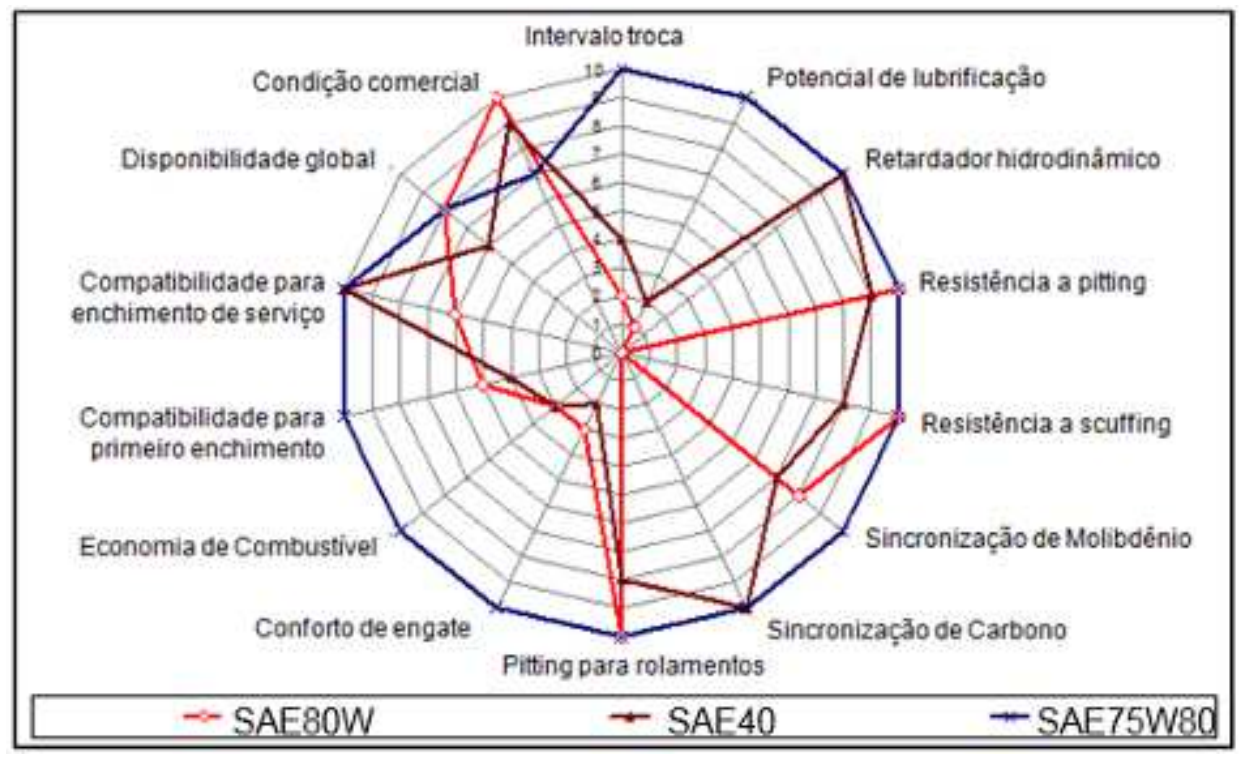

Figura 22 - Gráfico comparativo de desempenho de lubrificante para transmissões 


\subsubsection{Métodos revolucionários de desenvolvimento de novos fluidos}

Os fabricantes de aditivos são os principais desenvolvedores de tecnologia dos lubrificantes e utilizam testes padronizados ASTM para validar o desempenho de cada classe, seja SAE, API, ILSAC e outras. Em linhas gerais cada fabricante de lubrificante tem sua tecnologia de equipamento para ensaio e testes padronizados com aditivação particular, entretanto cada um irá seguir 4 etapas distintas: Laboratorial, componentes, bancos de prova e testes de campo, sendo esta sequência diretamente ligada aos custos de desenvolvimento, começando pelo laboratorial.

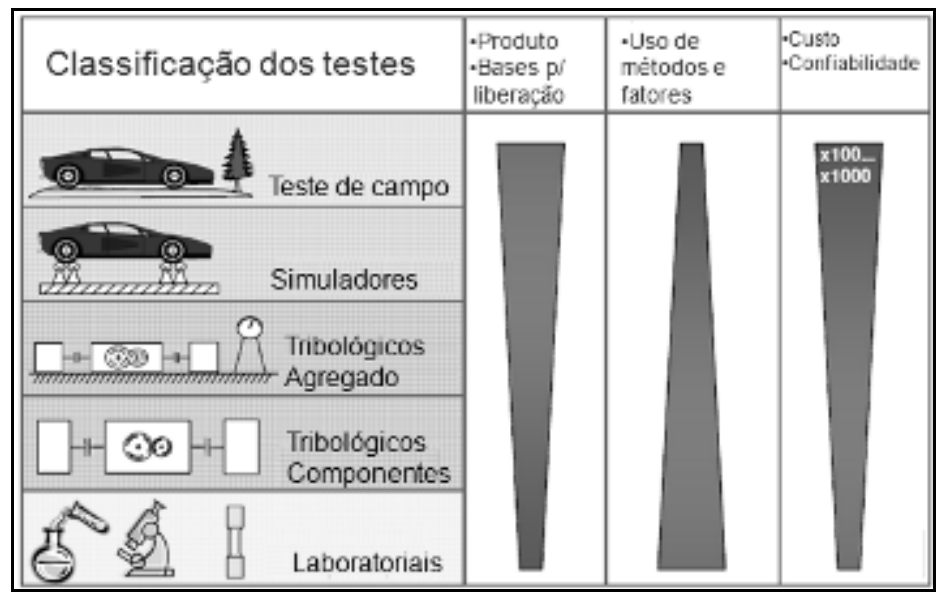

Figura 23 - Sequência de homologação de um lubrificante automotivo

Notavelmente uma pesquisa conduzida pelo instituto ISIS idealizou um método preditivo para se desenvolver um fluido, levando-se em conta sua complexidade química e lançando mão de modificações propositais podendo serem visualizadas de forma imediata por um aparelho de feixe de nêutrons. Com este equipamento pode-se ir além de uma difração de raio-X, podendo-se visualizar profundidades em sólidos de até $100 \mathrm{~mm}$ e em líquidos, pode visualizar na escala atômica o que está ocorrendo com as moléculas quando sujeitas a condições pré-determinadas de carga e aditivação, propiciando autonomia para entender as modificações cristalográficas da estrutura das moléculas do fluido considerado.

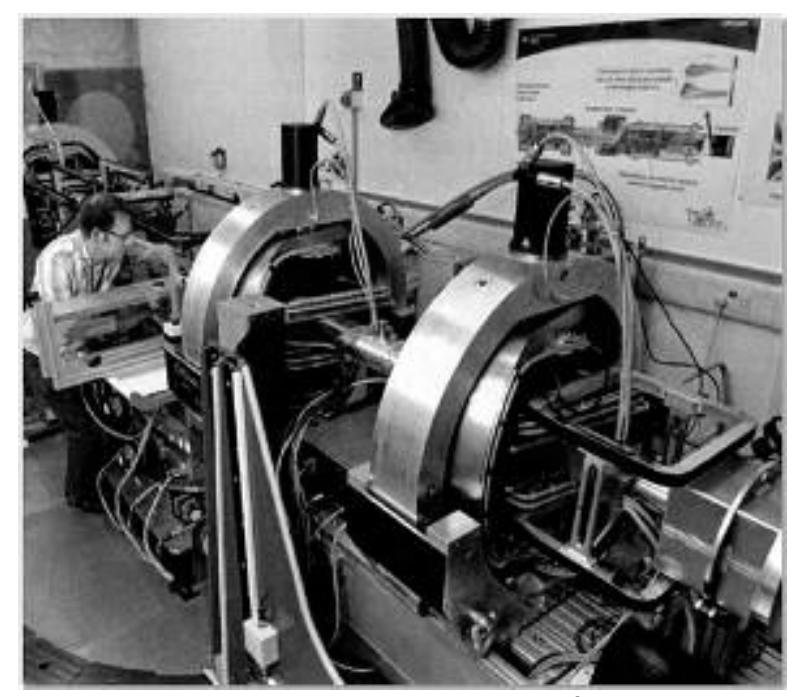

Figura 24 - Equipamento de feixe de Nêutrons da ISIS 


\section{CONSIDERAÇÕES FINAIS}

Com a evolução dos materiais e dos projetos assistidos na manufatura, os componentes automotivos passaram a ter um nível de confiabilidade conhecido, possibilitando a manutenção preventiva dos veículos em circulação constante. Consultas ao SINDIREPA [9] pode nos revelar a frequência de troca de peças e podemos refletir sobre o impacto do descarte das mesmas e projetar quais tecnologias devem ser usadas para se preparar o material para menor impacto ambiental. Fluidos e sólidos fazem parte deste montante que precisa ser gerenciado com cuidado para não incorrer em uma condição inviável de reciclagem e descarte de matéria-prima.

As empresas do segmento de autopeças de classe mundial, preparam-se para atenderem a exigências de mercado de forma eficaz, através de estudo das variáveis importantes de projeto por meios de cálculos, simuladores e bancos de teste, permitindo assim maximizar os resultados do equipamento, bem como otimizar os mesmos, pela observação dos resultados dos testes. A indústria automobilística e seus fornecedores estão focados em projetos e processos cada vez mais sofisticados para se obter produtos sustentáveis e tratar aqueles que demandam cuidados especiais no descarte [10]. A tabela abaixo informa o panorama atual de ciclo de vida de alguns materiais automotivos de acordo com sua classe de utilização para referência e análise da indústria.

\begin{tabular}{|l|l|l|}
\hline Família & Componente & Intervalo de troca (em anos) \\
\hline \multirow{4}{*}{ Químico } & Óleo Lubrificante & 0,81 \\
\cline { 2 - 3 } & Fluidos de freio & 2,09 \\
\cline { 2 - 3 } & Aditivos & 2,11 \\
\hline \multirow{4}{*}{ Elementrica } & Filtro de óleo & 1,32 \\
\cline { 2 - 3 } & Filtro de combustível & 1,68 \\
\cline { 2 - 3 } & Filtro de ar & 1,63 \\
\hline \multirow{5}{*}{ Freio } & Cabos de ignição & 3,67 \\
\cline { 2 - 3 } & Velas & 1,71 \\
\cline { 2 - 3 } & Baterias & 4,37 \\
\cline { 2 - 3 } & Lâmpadas & 1,37 \\
\hline Suspensão & Pastilhas de freio & 1,66 \\
\cline { 2 - 3 } & Discos de freio & 2,72 \\
\hline Distribuição & Amortecedores & 3,04 \\
\hline & Correias V E Poly-V & 2,84 \\
\cline { 2 - 3 } & Correias sincronizadas & 2,85 \\
\hline
\end{tabular}

Tabela 1. Intervalo de troca de peças automotivas segundo SINDIREPA 2017 


\begin{abstract}
NEW GENERATION OF AUTOMOTIVE POWERTRAIN AND DRIVELINE

The concept of mobility is now differentiated by the advent of environmental protection, so that current propulsion systems pass through the criterion of controlled emissions and the disposal of parts and fluids systematized. In order for all of this contemporary condition to be successfully achieved, the design and manufacture of the automotive components must be rethought in terms of its morphology and recyclability. Thus, technologies that provide only a good cost / benefit ratio in performance are not supported, since the impact on the life cycle of the equipment is above any technical consideration. This work aims to inform the reader in a structured and chronological way about the evolution of materials, fluids and projects that combine and make up the automotive propulsion and transmission systems. Understanding this evolution and reasoning about the function of each part in the mechanical and physicochemical systems under the clinical view of environmental preservation can lead a vehicle to compose the scenario of heavy urban traffic without diminishing the quality of life of the people who make use of this complex environment.
\end{abstract}

\title{
REFERÊNCIAS
}

[1] LEFFER, L. WILLIAM.; Petroleum Refining, In nontechnical language, $3^{\text {rd }}$ Ed., 2000.

[2] FRIEDRICH, MATHIAS.; Industrial Application of Topological, Shape and Bead Optimization, http://www.automotivebusiness.com.br, II Seminário AEA, São Paulo, 2010.

[3] BLANCO, RUY.; Curso SAE Brasil em Transmissões, $2^{\circ}$ Módulo, São Paulo, 2009.

[4] SPALTMANN, M. LÖHR.; In situ Acoustic Emission for wear life detection of DLC coatings during slip-rolling friction, Volume 260, Issues 4-5, 24, Pages 469-478, February 2006.

[5] MEFFERT, MICHAEL W.; Evaluation of factors affecting vehicle emission compliance using regional inspection and maintenance program data, SAE Technical paper, 2006-013406, 2006.

[6] MAHLE.; Desenvolvimentos para o Sistema de gerenciamento térmico e trem de força, São Paulo, paper, 2016.

[7] CUNNINGHAM, JUSTIN.; Polymers find use in engine transmissions, http://www.materialsforengineering.co.uk/engineering-materials-features, May $18^{\text {th }} 2018$.

[8] AUTOMOTIVE, ENGINEER.; Inside Renault's downsized engine range, July 32012 , Volume 120, Number 5.

[9] ANUARIO.; Indústria de reparação de veículos, SINDIREPA, Brasil, 2017.

[10] AUTOMOTIVE BUSINESS.; Lançamento de eixo 18X Meritor, http://www.automotive business.com.br/ , São Paulo, 2017. 